\title{
Фармакогенетическое тестирование антиагрегантных препаратов в кардиохирургической практике: клинический случай
}

\author{
Петрова О. В. ${ }^{1,2}$, Жукова Е. Р. ${ }^{1}$, Никулина Д. М. ${ }^{1}$, Шашин С. А. ${ }^{\text {, }, ~ Т а р а с о в ~ Д . ~ Г . ~}{ }^{1,2}$ \\ 1 - Федеральное государственное бюджетное учреждение «Федеральный центр сердечно-сосудистой хирургии» Ми- \\ нистерства здравоохранения Российской Федерачии, Астрахань, Россия \\ 2 - Федеральное государственное бюджетное образовательное учреждение высшего образования «Астраханский \\ государственный медицинский университет» Министерства здравоохранения Российской Федерации, Астрахань, \\ Россия
}

Ключевые слова: фармакогенетическое тестирование; антиагрегантные препараты; кардиохирургия

Для цитирования:

Петрова О. В., Жукова Е. Р., Никулина Д. М., Шашин С. А., Тарасов Д. Г. Фармакогенетическое тестирование антиагрегантных препаратов в кардиохирургической практике: клинический случай. Фармакогенетика и фармакогеномика. 2021;(2):8-10. (In Russ). https://doi.org/10.37489/2588-0527-2021-2-8-10

\section{Введение}

Ежегодно в ФГБУ «ФЦССХ» проводится около 1000 чрескожных транслюминальных коронарных ангиопластик (ЧТКА). В период с 2015 по 2020 год по результатам этих операций было выявлено около $9 \%$ случаев «клинической» и «лабораторной» резистентности к антиагрегантным препаратам, что привело к тромбозам стентов и послужило поводом для повторных операций. Мужской пол, наличие сопутствующей соматической патологии (сахарный диабет 2 типа, ожирение, артериальная гипертензия) являются негенетическими причинами резистентности к антиагрегантным препаратам [3]. Генетическая резистентность обусловлена полиморфизмом ферментов, участвующих в метаболизме антиагрегантных препаратов [1, 2]. Генетическую резистентность к антитромбоцитарным препаратам можно выявить с помощью лабораторных методов исследования, однако широкого применения данное исследование в клинической практике пока не нашло.

\section{Цель}

Показать на клиническом примере из кардиохирургической практики необходимость проведения исследований для определения генетической резистентности к антиагрегантным препаратам.

\section{Материалы и методы}

Диагноз «ИБС» установлен на основании отечественных рекомендаций. Пациент перед коронарографией и ЧТКА получил перорально нагрузочные дозы ацетилсалициловой кислоты (АСК) (препарат «Тромбо АСС», «Г.Л. Фарма», Гмбх, Германия) 300 мг и клопидогрела (Плавикс, «Санофи», Франция) 300 мг. Интраоперационно использовали нефракционированный гепарин (препарат «Гепарин-натрий Браун», «B. Braun Melsungen AG» Германия) 70 Ед/кг внутривенно болюсно. После операции пациент получал двойную антитромбоцитарную терапию (ДАТ): АСК 100 мг/сутки и клопидогрел 75 мг/сутки. Контроль за ДАТ осуществляли с помощью проведения ASPI-test (для чувствительности тромбоцитов к аспирину и его аналогам) и ADP-test (клопидогрел и его аналогам) методом импедансной агрегометрии на анализаторе «Multiplate» («Verum Diagnostica $\mathrm{GmbH»,} \mathrm{Германия).} \mathrm{Биологическим} \mathrm{материалом} \mathrm{являлась} \mathrm{кровь,} \mathrm{взятая} \mathrm{из} \mathrm{кубитальной} \mathrm{вены} \mathrm{в} \mathrm{одноразовые}$ полипропиленовые пробирки с литий-гепарином (Sarstedt, Германия). Оценку результатов исследования осуществляли с помощью сравнения полученных значений с целевым диапазоном, который при данном методе составил от 16 до 46 AUC: значения менее 46 AUC указывали на то, что тромбоциты чувствительны K антитромбоцитарным препаратам, более 46 AUC - не чувствительны [4].

Фармакогенетическое тестирование проводили с помощью полимеразной цепной реакции. Забор венозной крови производился в двухкомпонентную систему - одноразовые полипропиленовые пробирки с ЭДТА (Sarstedt, Германия). 


\section{Клиническое наблюдение}

Пациент Г., 53 года, русский, поступил в ФГБУ «ФЦССХ» (г. Астрахань), с диагнозом: «ИБС. Стенокардия напряжения, III функциональный класс» для плановой коронарографии с последующим определением объёма оперативного вмешательства на коронарных артериях. Масса тела при поступлении - 63 кг, рост - 169 см, индекс массы тела - 22. Коронарография выявила стеноз более 90 \% ПКА (правой коронарной артерии), в связи с чем была выполнена ЧТКА. В первые сутки после операции пациент находился в палате интенсивной терапии, далее переведён в кардиохирургическое отделение для дальнейшего лечения. Пациент в 1-е сутки после операции получал двойную ДАТ. Через 24 часа осуществлялся контроль: ASPI-test - 100 AUC, ADPtest - 125 AUC. На 2-е сутки после операции состояние пациента удовлетворительное, жалоб нет. Продолжал получать ДАТ. ASPI-test - 76 AUC, ADP-test - 120 AUC. На 3-е сутки после операции состояние пациента удовлетворительное, жалоб нет. Продолжал получать ДАТ. ASPI-test - 53 AUC, ADP-test - 117 AUC.

Учитывая клиническое состояние и данные инструментальных исследований (ЭКГ), пациент на 4-е сутки был выписан из стационара в удовлетворительном состоянии с рекомендацией продолжить ДАТ в течение 6 месяцев. Через месяц после выписки на фоне приёма ДАТ состояние пациента ухудшилось. Он повторно поступил в ФГБУ «ФЦССХ» (г. Астрахань) с жалобами на одышку. При поступлении результаты ASPI-test 43 AUC, ADP-test - 120 AUC. Проведена коронарография, выявлен тромбоз стента ПКА. Выполнена ЧTKA.

На основании результатов исследования чувствительности тромбоцитов к антиагрегантам и клиники тромбоза стента заподозрена резистентность к клопидогрелу. Взята кровь для фармакогенетического тестирования, результаты которого выявили полиморфизм СУР2С19 (аллели СУР2С19*2 и СУР2С19*3) и подтвердили наличие генетической резистентности пациента к клопидогрелу. В связи с этим отменён клопидогрел и назначен тикагрелор (90 мг 2 раза в день). Пациент наблюдался в течение 6 месяцев после последнего ЧТКА. Состояние пациента оставалось удовлетворительным, жалоб не было, повторных случаев тромбоза стента не наблюдалось.

\section{Результаты}

Частота встречаемости рискового вариантного аллеля $G$ составила $11,7 \%$, что соответствует данным по европейской популяции (13,7 \%; база ЕхАС). Доля лиц с гомозиготным генотипом $A A$, ассоциированным с нормальной чувствительностью к наркотическим анальгетикам, составила 77,8 \% (63/81). Носительство гетерозиготного рискового полиморфного варианта $A G$ было отмечено у $21,0 \%(17 / 81)$, тогда как гомозиготный генотип $G G$ был выявлен у 1,2 \% (1/81). Наибольшее число пациентов $(33 / 81)$ имело 2-ю стадию заболевания, что позволило сформировать сопоставимые группы сравнения. Отмечались статистически значимые различия в уровне восприятия болевого синдрома до начала противоболевой терапии: так, у лиц с генотипом $A A$ среднее значение ВАШ (M $\pm \mathrm{SE}$ ) составило $77,08 \pm 2,08$ мм, у лиц с генотипом $A G-87,78 \pm 2,95$ мм ( $p=0,0044$, тест Манна-Уитни), что свидетельствует об индивидуальных особенностях восприятия эндогенного ХБС. Средняя суточная доза оксикодона у больных с генотипом $A A$ составила $50,0 \pm 9,4$ мг, у лиц с генотипом $A G-93,3 \pm 15,7$ мг ( $p=0,0152$, тест Манна-Уитни).

\section{Заключение}

СУР2С19 - основной фермент, участвующий в метаболизме клопидогрела в печени. Генетическая вариабельность является причиной его полиморфизма, различают СУР2С19*1, СУР2С19*2 и СУР2С19*3 [5]. Две последние изоформы ответственны за нарушение реакции ингибирования тромбоцитов на фоне приёма клопидогрела с риском повторных сердечно-сосудистых событий. Приведённый нами клинический пример указывает на наличие варианта генетической резистентности к клопидогрелу.

Таким образом, фармакокинетическое тестирование пациентов с сердечно-сосудистой патологией на дооперационном этапе может позволить снизить частоту развития нежелательных повторных послеоперационных сердечно-сосудистых событий, а, следовательно, улучшить качество оказания медицинской помощи.

\section{Список литературы / References}

1. Айнетдинова Д.Х. Резистентность к антитромбоцитарным препаратам у больных с ост-рым коронарным синдромом без подъёма сегмента ST. Кардиология. 2008;48(6):35-39. [Ajnetdinova DH. Rezistentnost' k antitrombocitarnym preparatam u bol'nyh s ostrym kor-onarnym sindromom bez pod»yoma segmenta ST. Kardiologiya. 2008;48(6):35-39. (In Russ).].

2. Петрова О.В., Мурыгина О.И., Никулина Д.М., Шашин С А., Полухина А.Л., Малахова Л.Г., Тарасов Д.Г. Значение определения чувствительности тромбоцитов в клинической практике. Астраханский медицинский журнал. 2021;16(3):34-40. [Petrova OV, Murygina OI, Nikulina DM, Shashin SA, Tarasov DG. The value of determining the sensitivity of platelets in clinical practice. Astrakhan Medical Journal. 2021;16(3):34-40. (In Russ).]. DOI: $10.17021 / 2021.16 .3 .34 .40$. 
3. Петрова О.В., Шашин С.А., Тарасов Д.Г. Референтные значения агрегации тромбоцитов при исследовании импендансным методом с аденозиндифосфорной кислотой на агрегометре MULTIPLATE. Современные технологии в медицине. 2016;8(3):100-104. [Реtrova O.V., Shashin S.A., Tarasov D.G. Reference values of platelet aggregation in impedance aggregometry with adenosine diphosphoric acid on aggregometer multiplate. Sovremennye tehnologii v medicine. 2016;8(3):100-104. (In Russ).]. DOI: 10.17691/stm2016.8.3.11.

4. Сычев Д.А., Торбенков Е.С. Клиническая фармакогенетика антиагреганта тикагрелора: есть ли перспективы? Фармакогенетика и Факмакогеномика. 2016;(2):24-26. [Sychev DA, Torbenkov ES. Clinical pharmacogenetics of ticagrelor: is there prospect? Farmakogenetika i farmakogenomika = Pharmacogenetics and pharmacogenomics. 2016;(2):24-26. (In Russ).]

5. Шишкина Т.А., Наумова Л.И., Никулина Д.М. Действие ДНК-аптамеров (ингибиторов) тромбина на микроциркуляторное русло легких при экспериментальной гипоксии. Морфология. 2012;141(3):180. [SHishkina TA, Naumova LI, Nikulina DM. Dejstvie DNK-aptamerov (ingibitorov) trombina na mikrocirkulyatornoe ruslo legkih pri eksperimental'noj gipoksii. Morfologiya. 2012;141(3):180. (In Russ).].

\title{
Возможности и перспективы фармакогенетического исследования в городе Петрозаводск
}

\author{
Кирсанова Н. А., Юнаш В. Д. \\ ФГБОУВО «Петрозаводский государственный университет» \\ Ключевые слова: фармакогенетические исследования \\ Для цитирования: \\ Кирсанова Н. А., Юнаш В. Д. Возможности и перспективы фармакогенетического исследования в городе Петрозаводск. Фарма- \\ когенетика и фармакогеномика. 2021;(2):10-11. (In Russ). https://doi.org/10.37489/2588-0527-2021-2-10-11
}

\section{Введение}

В настоящее время персонализированный подход находит всё большее отражение в медицинской практике. Фармакогенетическое тестирование, основанное на выявлении определённых генотипов у конкретного пациента, ассоциированных с изменением фармакологического ответа, позволяет установить наблюдение за отклонениями и сформировать рекомендации по оптимальному выбору лекарственных средств пациенту и их дозированию [1]. Применение фармакогенетических тестов даёт возможность повысить эффективность назначенной лекарственной терапии, с одной стороны, и снизить возможные риски применения лекарственных препаратов, с другой [2]. Однако данные фармакогенетические подходы в персонализированной медицине распространены неравномерно. В связи с этим представляется актуальным оценить возможности проведения фармакогенетических исследований в городе Петрозаводск, что и легло в основу данной работы.

\section{Цель}

Определение возможностей и перспектив фармакогенетического исследования в городе Петрозаводск.

\section{Материалы и методы}

Исследование проведено в декабре 2021 года. Были изучены и проанализированы прайс-листы 10 лабораторий города Петрозаводск (Республика Карелия), размещенные на сайтах организаций в открытом доступе. Сравнение проводилось по 5 параметрам: наличие или отсутствие фармакогенетических исследований в прайс-листе, виды проводимых тестов, их стоимость, наличие или отсутствие описания исследования, а также наличие или отсутствие по результатам тестирования заключений врача-генетика. Методы, которые были использованы в работе: анализ и синтез.

\section{Результаты}

По данным, полученным при анализе открытых источников лабораторий города Петрозаводск, было выявлено, что возможности для проведения фармакогенетического тестирования на уровне г. Петрозаводск имеются, однако данные исследования осуществляются только в 3 из 10 лабораториях города - «Гемотест», «INVITRO», «Инто-стил».

Стоит отметить, что линейка тестов для исследований существенно отличается в данных лабораториях. Фармакогенетическое тестирование в лаборатории «Гемотест» проводится только для 4 позиций - это иссле- 